\title{
Research on the Effect of the Different Empathy Ability of Supervisor on the Turnover Intention in the Organizational Culture
}

\author{
Chang soo $\mathrm{Han}^{1}$, Yen Yoo You ${ }^{2} \&$ Seon Ji Kim ${ }^{1}$ \\ ${ }^{1}$ Strategy Business Team, Good Neighborhood. co., Hannuri-daero, Sejong-si, South Korea \\ ${ }^{2}$ Dept. of Smart Convergence Consulting, Hansung University, Seoul Metropolitan Government, South Korea \\ Correspondence: Chang soo Han, Doctor of Consulting, Senior Researcher, Strategy Business Team, Good Neighborhood. \\ co., Hannuri-daero, Sejong-si, South Korea. Tel: 82-2-760-4392, 82-10-7587-4392. E-mail: mastercne@ naver.com
}

Received: April 9, 2020

Accepted: May 9, 2020

Online Published: May 23, 2020

doi:10.5430/rwe.v11n2p165

URL: https://doi.org/10.5430/rwe.v11n2p165

\begin{abstract}
Background/Objectives: This research is made to find out what kind of moderating effect the empathy ability of supervisor makes on the turnover intention in the hierarchical organizational culture.

Methods/Statistical analysis: The subjects for this research are the employees working for small and mid-sized companies in Korea and the questionnaires were distributed to them for the research. The questionnaire was made up of 16 questions including 4 demographical questions and the measuring was made by using 5 -point Likert scale. For the empirical analysis, SPSS 23.0 program was used and the feasibility analysis, reliability analysis, regression analysis and the test of moderating effect were performed.

Findings: As the number of independent variable was just one, the factory analysis was not conducted. The results of reliability analysis showed that Cronbach Alpha values were all 0.6 or more. In addition, the correlation analysis results showed that the correlation between the hierarchical organizational culture and turnover intention was 0.931 and the correlation between the hierarchical organizational culture and the empathy ability of supervisor was 0.242 , thus showing the low correlation. On the other hand, the correlation between the turnover intention and the empathy ability of supervisor was 0.661 , thus showing a little high correlation. All of them showed the significance probabilities of 0.0000 . The regression analysis showed that the hierarchical organizational culture made a significant effect on the turnover intention. As the analysis of moderating effect shows the increase in the value $\mathrm{R}^{2}$ with the significance probability of less than 0.05 , it was confirmed that the empathy ability of supervisor has the moderating effect. This means that even though the hierarchical organizational culture may affect the turnover intention, the empathy ability of supervisor may lower the turnover intention.
\end{abstract}

Improvements/Applications: The future researches are required to focus on the methodology of enhancing the empathy ability and the tools for measuring the empathy ability along with the development of program.

Keywords: human resources management, organizational culture, hierarchical organizational culture, turnover intention, empathy ability

\section{Introduction}

The turnover of a member is a big loss to a company. A company makes a lot of investment in training its personnel. So, if the trained personnel early leave the company, the company is not able to get back the investment. In that case, the company needs to train new personnel and grow their abilities to the company's work, thus leading to the waste of company's time and investment in labor. To prevent such losses, a lot of companies are trying to activate the organization from the perspective of human resources management. All companies recognize the importance of organizational culture and, to get more flexible culture, they get a lot of consulting services. The fact that the organizational culture affects the employee's turnover intention has been confirmed through the prior researches. Those researches have shown that the organizations which put emphasis on the strict discipline such as military organization or hierarchical system have more members who intend to leave the organizations. But, as the compensation, welfare or leadership may change the turnover intention, we tried to check if the empathy ability of supervisor can moderate the employee's turnover intention. The empathy ability has the property of emotion and capability. Even in the management consulting and the design thinking which are the innovative methodologies in 
management, the importance of the empathy ability has been proved. Even in the marketing, it is used as the emotional marketing technique which stimulates the emotion. So, this research tries to check how the empathy ability of supervisor would affect the employee's turnover intention by using the hierarchical organizational culture which puts emphasis on the strict discipline as an independent variable, the turnover intention as the dependent variable and the empathy ability of supervisor as the moderator variable.

\section{Materials and Methods}

\subsection{Human Resources Management}

As for the concept of human resources management, it has been defined as a decision making pattern for the implementation of strategy, for selection, keeping, and development of the human resources and creating the competitive edge in order to achieve the organizational objectives in 1980s. In 1990s, the companies put emphasis on the technique and systems which would integrate the human resources' activities, harmonize the employees with the other business strategy in addition to the human resources management strategy and achieve the organizational goals through the member's voluntary participation. But, since 2010, the focus has changed to the wide-range of activities such as the prediction of the demand for human resources, the acquisition of talented human resources, and the displacement, design, development and training of them. This may be called as the activities which achieve the corporate strategic goals and link the human resources management to the strategic goals for the development of organizational culture along with the innovation and facilitation of flexibility through the harmony of functions which the human resources have rather than the human resources management only. (Schein, 1980) (Ivancevich, 1995) (Lee, 2019)

\subsection{Organizational Culture}

The organizational culture is the culture which all members of an organization share in the organization or the value which is more than the social or normative values which the organization shares. It can be defined as a total concept including the value, tradition, knowledge, practice and technologies which an organization has. (Pettigrew, 1979) (Kim, 2016)

\subsection{Hierarchical Organizational Culture}

Among the organizational cultures, the hierarchical organizational culture is even called the internal process model and reflects the norm or value of the hierarchy which puts emphasis on the official order, rule or authoritative control. This kind of organizational culture gets the strict control process which puts emphasis on the relation between subordinates and superiors, rank and the submission. But if the control is too much emphasized, the members try to avoid the responsibility and punishment, thus leading to the weakened motivation and passion for the work, which in in turn leading to the decrease in the job satisfaction. A lot of people may consider the vertical organization to have the hierarchical culture. But, the vertical organization is the organizational form which is used by most of the companies as it enables a few people to control the entire organization. Contrary to that, the hierarchical organizational culture gets the organizational form which is strict in the work rule, process and rank and, based on that, strengthens the control over the members. (Kim, 2015) (Cho, 2010)

\subsection{Turnover Intention}

The turnover intention is defined as the psychological status in which a member of an organization wants to quit the organization. It focuses on whether this psychological status has been voluntarily made. Although the turnover intention does not mean the immediate quit, it can make the negative effect on the employees' organizational loyalty and can be shown as the anti-organizational activities such as lateness or absence (Moon, 2010) (Anwana et al., 2019); (Ariani, 2017); (Asafo et al., 2019).

\subsection{Empathy Ability}

The empathy ability means a person's recognition and feeling of other people's emotion, thinking and experience. This can be said the emotional skill. The empathy ability can be defined as a person's ability of reading the other people's thinking or emotion through the empathy (Ann and Kathy, 2013) (Han, 2019). 


\subsection{Study Model and Hypothesis}

\subsubsection{Study Model}

In this research, the hierarchical organizational culture was used as an independent variable, the turnover intention as a depending variable and the empathy ability as a moderator variable as shown in the research model Figure 1.

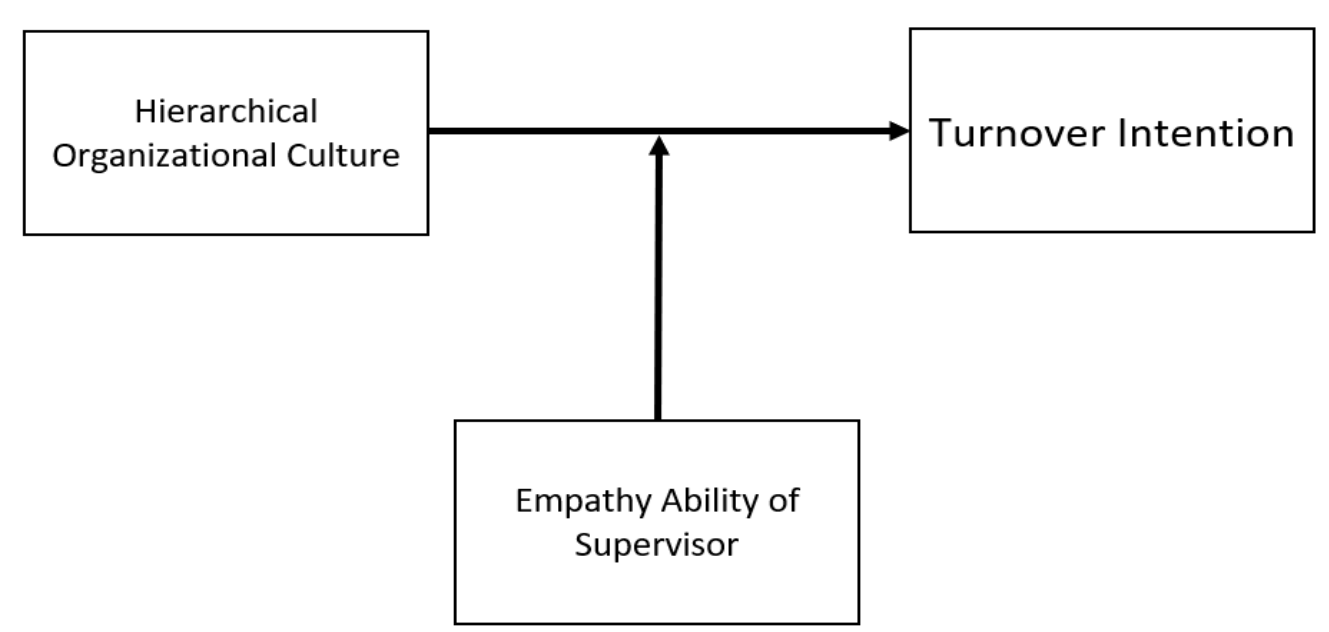

Figure 1. Research model

\subsubsection{Hypothesis}

Hypothesis 1 (H1): The hierarchical organizational culture makes the positive (+) effect on the turnover intention.

Hypothesis 2 (H2): The empathy ability of supervisor makes the moderating role on the relation between hierarchical organizational culture and the turnover intention.

\subsubsection{Research Tools and Operational Definitions of Variables}

There are many empirical analysis methods. The questionnaire technique was used for this research. To get the statistical and realistic significance of the research, the selection of targets for the questionnaires is critical. The target people for this questionnaire were the employees of small and medium-sized enterprises (SMEs) located in Korea. 300 copies of questionnaires were distributed to the subjects and among them, 250 copies were returned with the rate of recovery being $83.3 \%$. In this research, the measurement variables include 3 items such as the hierarchical organizational culture, turnover intention and empathy ability while as the research tools, the items suggested in the research made by Park Beom-seok (2019) and prior researches were used. The items in the questionnaire are made of 5 questions related to demography, 4 questions related to the hierarchical organizational culture, 4 questions on turnover intention and 4 items on the empathy ability. The measuring adopted 5-point Likert scale. (Park, 2019)

\section{Results and Discussion}

\subsection{Proof Analysis Results}

\subsubsection{Demographic Characteristic Analysis}

Among 250 companies, there were 12 listed companies (4.8\%) and 238 non-listed companies (95.2\%). 39 companies had the history of less than 3 years, and 32 companies have the history of at least 3 years but less than 5 years. In addition, there were 69 companies having the history of at least 5 years but less than 10 years and 108 companies having the history of at least 10 years. 124 companies were located in Seoul, Gyeonggi or Incheon (49.6\%) while the remaining 126 companies were located in other regions.

34 companies have the employees of no less than 100 (13.6\%) and the rest of the companies were found to have the employees of no more than 100. In the field of industry, 208 companies were involved in manufacturing (83.2\%) and the rest of the companies were involved in non-manufacturing industries (16.8\%).

\subsubsection{Reliability Verification and Validity of Research Tools}

By using SPSS 23 program, the reliability analysis has been conducted for 12 questions excluding 5 demographical 
questions. As an independent variable was one of the factors, the factor analysis was not conducted. The reliability analysis results showed that as the Cronbach Alpha value is 0.6 or more, all question items were used as the research tools (Ali and Harvie, 2015); (Amoroso and Ackaradejruangsri, 2019).

\subsubsection{Correlation Analysis}

The correlation analysis results showed that the correlation between the hierarchical organizational culture and turnover intention was 0.931 and the correlation between the hierarchical organizational culture and the empathy ability of supervisor was 0.242 , thus showing the low correlation. On the other hand, the correlation between the turnover intention and the empathy ability of supervisor was 0.661 , thus showing a little high correlation. All of them showed the significance probabilities of 0.0000 . All these show that the hypotheses were well established.

\subsubsection{Testing the H1 Hypothesis}

As the hypothesis $\mathrm{H} 1$ "The hierarchical organizational culture makes the positive $(+)$ effect on the turnover intention" was adopted as it was found to be statistically significant in the significance level of $5 \%$ with $\mathrm{P}$ value of $0.000, \mathrm{~F}$ changes of 44.808 and Durbin-Watson of 2.127 as shown in Table 1.

Table 1. Verification of Hypothesis H1

\begin{tabular}{cccccc}
\hline $\begin{array}{c}\text { Dependent } \\
\text { Variable }\end{array}$ & $\begin{array}{c}\text { Independent } \\
\text { Variable }\end{array}$ & Standardized Error & $\boldsymbol{\beta}$ & $\mathbf{t}$ & $\mathbf{P}$ \\
\hline Turnover & $\begin{array}{c}\text { Constant) } \\
\text { Intention }\end{array}$ & .247 & & 7.284 & .000 \\
& $\begin{array}{c}\text { Hierarchical organizational } \\
\text { culture }\end{array}$ & .063 & .391 & 6.694 & .000 \\
\cline { 2 - 5 } & $\mathrm{R}=.391, \mathrm{R}^{2}=.153$, Modified $\mathrm{R}^{2}=.0 .150, \mathrm{~F}=44.808, \mathrm{P}=.000$ \\
\hline
\end{tabular}

\subsubsection{Testing the H2 Hypothesis}

As the hypothesis $\mathrm{H} 2$ on the moderating effect, "The empathy ability of supervisor makes the moderating role on the relation between hierarchical organizational culture and the turnover intention" was also adopted as it is found to be statistically significant in the significance level of $5 \%$ with the increasing $\mathrm{R}^{2}$ of $0.153,0.493$ and 0.509 and $\mathrm{F}$ changes of significant probability being 0.005 , which is below 0.05 as shown in Table 2 .

Table 2. Verification of Hypothesis H2

\begin{tabular}{ccccc}
\hline Dependent Variable & Model & Variables Entered & $\mathbf{R}^{2}$ & Significance F Variation \\
\hline Turnover & 1 & Hierarchical organizational culture & .153 & .000 \\
Intention & 2 & Empathy Ability of Supervisor & .493 & .000 \\
& 3 & Interaction term & .509 & .005 \\
\hline
\end{tabular}

\section{Conclusion}

\subsection{Study Results and Implications}

The research results showed that as shown in the prior researches, the hierarchical organizational culture makes the effect on the turnover intention. This means that the severely restrictive organizational culture and many controls in the organization lead the members to leave the organization. In addition, it was found that the empathy ability of supervisor has the moderating effect on turnover intention in the hierarchical organizational culture. This means that even though an organization strengthens the order and principle and is a vertical and restrictive one, the empathy ability of supervisor can make the increase or decrease the turnover intention.

\subsection{Improvement}

This research is designed to verify the moderating effect of empathy ability of supervisor on the relation between hierarchical organization culture and turnover intention. It had been already proved at the innovative methodologies of design thinking and inquiry model of consulting that the empathy ability which has the properties of emotion and 
capability is the critical factor. In this research, it is proved that the empathy ability of supervisor makes the big effect on the turnover intention. But, this research has its own limitation in that the measuring tool of the empathy ability of supervisor may not represent all of the empathy ability of supervisor and that the subjects may not accurate recognize the empathy ability of supervisor. In the future research, the follow-up researches on the development of methodology, and tool and the in-depth researches on the development of measuring tools in order to enhance the empathy ability.

\section{Acknowledgment}

This research was financially supported Hansung University graduate school.

\section{References}

Ali, I., \& Harvie, C. (2015). Oil production rehabilitation, fiscal policy and economic development in Libya: A future view. Energy Economics Letters, 2(1), 1-23.

Amoroso, D. L., \& Ackaradejruangsri, P. (2019). Satisfaction with applications fuels the growth of mobile wallet use in Thailand. International Journal of Business, Economics and Management, 6(1), 16-22.

Ann, K. B., \& Kathy, E. (2013). Consulting in uncertainty: Power of inquiry. New York: Routledge.

Anwana, E. O., Udo, A. B., \& Affia, S. E. (2019). Agricultural value added, governance and insecurity in Nigeria: An empirical analysis. Asian Business Research Journal, 4, 1-9.

Ariani, D. W. (2017). Good soldiers and good actors: Is there any differences?. International Journal of Asian Social Science, 7(1), 31-44.

Asafo, S. S., Matuka, A., \& Dominic, N. (2019). External debt and economic growth: Two-step system GMM evidence for Sub-Saharan Africa countries. International Journal of Business, Economics and Management, $6(1), 39-48$.

Cho, S. (2010). Effect of public sport facility management corporations' cultural and environment factors on service orientation and customer orientation, Konkuk University, Korea. Retrieved from http://www.riss.kr/link?id=T12088796

Han, C.-S. (2019). A study on the effects of trust relationship and partnership between consultant and client on the consulting performance: Focusing on the mediating effects of empathy ability, graduate school of Hansung University, Korea. Retrieved from http://www.riss.kr/link?id=T15356308

Ivancevich, J. M. (1995). Human resource management (Int led.). NY: McGraw-Hill.

Kim, E. (2015). A study of the causal relationship between organizational culture and affective commitment of general hospital administrative staff - control effects of sectoral types and employment types, Myongi University, Korea. Retrieved from http://www.riss.kr/link?id=T13865717

Kim, J. H. (2016). A study on the effects of organizational conflict on organizational effectiveness in the government organizations - focus on the moderating effects of leadership and organizational culture, Graduate School of Chonnam National University, Korea. Retrieved from http://www.riss.kr/link?id=T14208943

Lee, S.-S. (2019). The role of jewelry employees strategic human resource management on organizational effectiveness: Moderating effect of social support, Kyonggi University, Korea. Retrieved from http://www.riss.kr/link?id=T15047493

Moon, Y.-J. (2010). Effects of individual motivation on turnover intention among social workers - with a focus on the mediation effects of multiple commitment, Graduate School, Seoul National University, Korea. Retrieved from http://www.riss.kr/link?id=T12194496

Park, B.-S. (2019). Sulting satisfaction and business performance: Based on the control variables of consulting understanding and participation, Graduate School of Hansung University, Korea. Retrieved from http://www.riss.kr/link?id=T15067069

Pettigrew, A. M. (1979). On studying organizational cultures. Administrative Science Quarterly, 24(4), 570-581. Retrieved from https://www.jstor.org/stable/2392363?seq=1

Schein, E. H. (1980). Organizational psychology. Englewood Cliffs, NJ: Reprinted by Permission of Prentice-Hall, Inc. 